\title{
Inheritance of the $O$ Antigens of Salmonella Groups B and D
}

\author{
BY P. HELENA MÄKELÄ \\ Guinness-Lister Research Unit, Lister Institute of Preventive Medicine, \\ Chelsea Bridge Road, London, S.W. 1 and Department of Serology and \\ Bacteriology, University of Helsinki, Helsinki, Finland
}

(Received 9 March 1965)

\begin{abstract}
SUMMARY
The inheritance of the $\mathrm{O}$ antigens of Salmonella was studied by $\mathrm{H} f \mathrm{r} \times \mathrm{F}^{-}$ crosses of strains of groups $B$ (antigens 4,5,12) and D (antigens 9,12). The partial antigens 4 and 9 behaved as if determined by allelic loci, in the sense that all recombinants had either antigen 4 or antigen 9 ; never both or neither of them. The $O-4 / 9$ locus thus defined was rather closely linked to $h i s$, the locus for histidine biosynthesis. The gene $O-5$ determining the presence or absence of partial antigen 5 (an $\mathrm{O}$-acetyl group on a galactose unit) in group B was very probably introduced into a number of $\mathbf{9 , 1 2}$ recombinants. No antigen 5 appeared. The $O-5$ locus was also found to be linked to $O-4 / 9$ and $h i s$ but the linkage was less close than that between $O-4 / 9$ and his. It is suggested that the loci $O-4 / 9$ and possibly $O-5$ are part of a large $O$-locus concerned with the synthesis of the specific side-chains of the somatic lipopolysaccharide, which perhaps includes the rou-B locus of Subbaiah \& Stocker (1964).
\end{abstract}

\section{INTRODUCTION}

The specificity of the various somatic or $O$ antigens of enteric bacteria, e.g. Salmonella, resides in a lipopolysaccharide (LPS) component of the cell wall. More precisely, the structures responsible for the specificity are relatively short repeating sequences, 'repeat units', of monosaccharides which constitute the 0-specific part of polysaccharide side-chains (Staub, 1964; Robbins \& Uchida, 1962). The innermost portions of the side-chains and the backbone to which these are attached form a 'core' probably common to all Salmonella species, irrespective of their antigenic character (Kauffmann, Krüger, Lüderitz \& Westphal, 1961; Lüderitz, Beckmann \& Westphal, 1964). The main features of this structure are apparent from the diagram of Fig. 1.

A number of different mutations are known that result in a defective lipopolysaccharide, all bacteriologically recognized as rough $(\mathrm{R})$ forms and apparently possessing a more or less complete core but not the specific parts of the side-chains. Of special interest among them are rou-B mutants whose lipopolysaccharides have the antigenic type called $\mathbf{R}_{\text {II }}$ (Subbaiah \& Stocker, 1964: Beckmann, Subbaiah \& Stocker, 1964; Beckman, Lüderitz \& Westphal, 1964). These seem to have the complete core, with $\mathrm{N}$-acetylglucosamine as the terminal monosaccharide unit (Osborn et al. 1964). Different enzymic defects can result in this same phenotype: defective rhamnose synthesis in one case, unknown defects in many others (Nikaido, 
Nikaido, Subbaiah \& Stocker, 1964). Since the rou-B mutants are by definition genetically linked to his, the locus of histidine biosynthesis, it is likely that they occur in a perhaps large region of the chromosome which is concerned with the synthesis of the $\mathrm{O}$-specific part of the side-chains. This region could reasonably be called an $O$ locus. Earlier, a locus controlling the specificity of the $\mathbf{O}$ antigen in Escherichia coli was mapped near his (Ørskov \& Ørskov, 1962); this could well be the same locus.

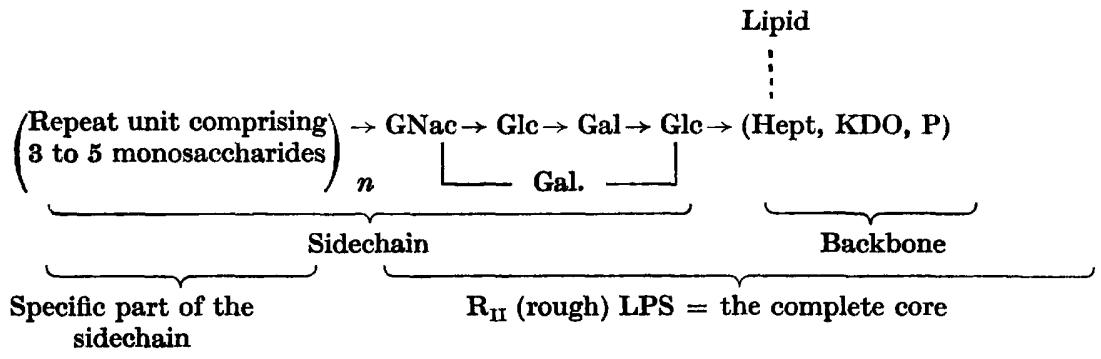

' GNac $=$ N-acetyl-D-glucosamine; Glc $=$ D-glucose; Gal $=$ D-galactose; Hept $=$ L-glycero-Dmannoheptose; $K D O=2$-keto-3-deoxyoctonic acid; $P=$ phosphate; LPS $=$ lipopolysaccharide.

Fig. 1. A schematic representation of the somatic lipopolysaccharide of Salmonella (mainly according to Osborn et al. 1964). The structure of some 0 repeat units is shown in Fig. 8.

Serologically, each specific $\mathbf{O}$ antigen is a composite of various partial antigens (Kauffmann, 1954). These partial antigens represent different aspects of the same lipopolysaccharide molecule (Furth \& Landsteiner, 1929; Staub \& Pon, 1956; Lüderitz, O'Neill \& Westphal, 1960), and possibly of the same repeating unit (Robbins \& Uchida, 1962; Uchida, Robbins \& Luria, 1963). The antibodies used for identifying the partial antigens recognize a structure definitely larger than a monosaccharide, and probably of the order of a tri- or tetra-saccharide. However, the non-reducing mono- and di-saccharides at the ends of side-chains, and/or their branches, play a prominent role in the specificity (Staub, Tinelli, Lüderitz \& Westphal, 1959; Staub, 1964).

The present work was started in the hope of eventually clarifying the genetic determination of the specific side-chains of the somatic lipopolysaccharide. Salmonella species seemed to offer several advantages over Escherichia coli, even though the work was started with the latter (Ørskov \& Ørskov, 1962). The Salmonella antigens have been more exhaustively classified both serologically (Kauffmann, 1954) and chemically (Kauffmann, Lüderitz, Stierlin \& Westphal, 1960; Uchida et al. 1963; Staub, 1964). The usual absence of capsular antigens in Salmonella organisms makes them technically easier to analyse. The recent development of an effective $\boldsymbol{H} \mathrm{fr}^{-} \rightarrow \boldsymbol{F}^{-}$conjugation system permitting inter-species and inter-O-group crosses in Salmonella was a necessary prerequisite for this genetic analysis (Mäkelä, 1963). Two questions seemed to be of special interest: (1) whether one would find allelic genes concerned with the determination of the alternative specificities of polysaccharide structures; (2) to what extent the partial antigens would be independently determined, e.g. whether it would be possible to synthesize new combinations thereof? 


\section{METHODS}

Bacterial strains. Those used came from the author's collection in Helsinki (sH and sw strains) or from the collection of the Guinness-Lister Research Unit at the Lister Institute, Chelsea Bridge Road, London, S.W. (sL strains).

Group B $(4,5,12)$ bacteria:

sw 1444. Salmonella abony Hfr met- aro- str-r H1-b H 2-e,n,x, which is identical with sw 1391 of Mäkelä (1963).

SL 803. S. typhimurium LT-2 F- hisD 37- athA 2- str-r H 1-i H 2-1,2.

SH 142. S. typhimurium LT-2 $F^{-}$his $^{-}$phe- H 1-i H 2-1,2.

Group D $(9,12)$ bacteria:

SH 673. Salmonella enteritidis $F$ 59+ try- H1-g, $m$. The $F^{\prime}$ episome, $F$ 59, converts bacteria carrying it into donors of the same type as sw 1444 (Mäkelä \& Ziegler unpublished).

SH 674. S. enteritidis $\mathrm{F}^{-}$his $^{-}$try- $\mathrm{H}$ 1-g,m.

The location of markers and origins and directions of chromosome transfer of the donor ( $H f r$ and $\mathrm{F} \mathrm{F}^{+}$) strains, as well as abbreviations used are given in Fig. 2. $F^{-}$or $=$female recipient strain.

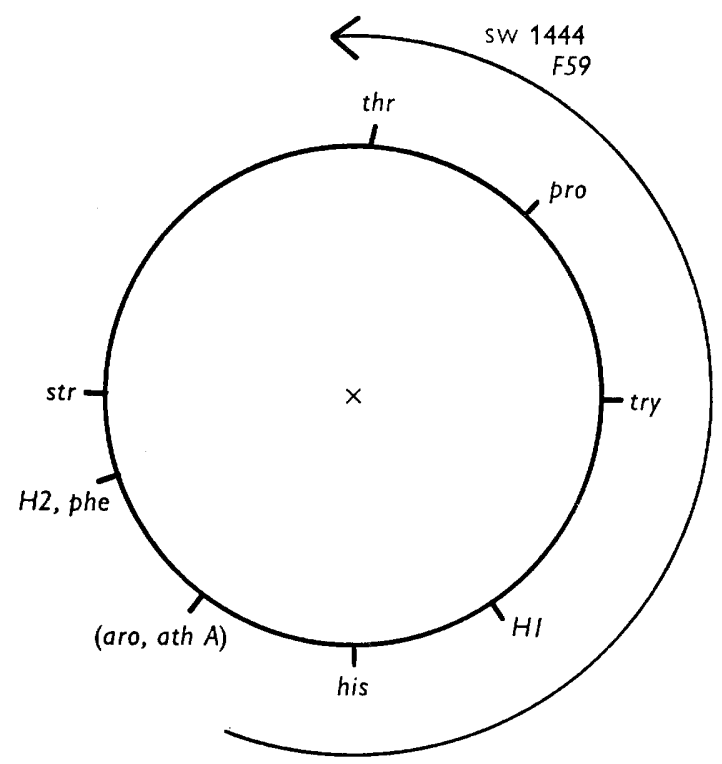

Fig. 2. A chromosome map of Salmonella showing the approximate location of markers and the point of origin (point of the arrow) and direction of transfer of the donor strains (according to Smith \& Stocker, 1962 and personal communication; Mäkelä, 1963; Mäkelä \& Ziegler, unpublished). thr, threonine requirement; pro, proline requirement; try, tryptophan requirement; his, histidine requirement; aro, phenylalanine and tyrosine requirement; ath, adenine and thiamine requirement; phe, phenylalanine requirement; str, streptomycin resistance; $H 1$, phase-1 flagellar antigen; $H 2$, phase-2 flagellar antigen.

Culture media. Broth: Difco nutrient broth $+0.5 \% \mathrm{NaCl}$. Nutrient agar: Difco nutrient broth $+1 \cdot 6 \%$ agar. Motility medium: Difco nutrient broth $+0.5 \%$ agar $+8 \%$ gelatin (Stocker, Zinder \& Lederberg, 1953). Defined medium: Davis 
minimal medium (Lederberg, 1950): $1 \cdot 6 \%$ agar, $0.2 \%$ glucose, amino acids and/or adenine, $20 \mu \mathrm{g} . / \mathrm{ml}$; thiamine, $0.002 \mu \mathrm{g} . / \mathrm{ml}$.; streptomycin, $1000 \mathrm{ug} . / \mathrm{ml}$. when indicated.

Crosses were made between exponentially growing cultures of $\mathrm{H} f r$ or $\mathrm{F}_{59^{+}}$donor and $F^{-}$recipient mixed so as to give about $5 \times 10^{7}$ donor bacteria $/ \mathrm{ml}$. and $5 \times 10^{8}$ recipient bacteria. This mating mixture was kept undisturbed at $37^{\circ}$ for $2 \mathrm{hr}$, then plated without washing on selective defined medium. Recombinant colonies which appeared after 2 days were streaked on nutrient agar, from which single colonies were picked and tested for their growth requirements and antigenic characters.

$H$ antigens were determined by slide agglutination in rabbit anti-H sera diluted 1/100. Before testing, the strains (or recombinants) were passed through motility medium to enhance their motility.

$O$ antigens were determined by slide agglutination in appropriate antisera at predetermined dilutions. Single factor sera anti-4 and anti-9 were a gift from the Serological Standards Laboratory, Central Public Health Laboratory, Colindale, London, N.W. 9. Anti-5 factor serum was prepared by absorbing an anti-4,5,12 serum with strain SL 681 of Salmonella typhimurium, an LT2 mutant which lacks antigen 5. An unabsorbed serum against $S$. paratyphi $A$ (O antigens 2, 12), also from the Standards Laboratory, was used as an anti-12 reagent.

\section{RESULTS}

Cross 1 was between a 4,5,12 Salmonella abony donor and a 9,12 S. enteritidis recipient; the outcome is seen in Table 1 . In bacterial crosses most recombinants resemble the recipient parent more than the donor parent, having inherited only a

Table 1. Cross 1. 4,5,12 donor Salmonella abony Hfr sw 1444 (met- aro- str-r H1-b $H 2-e, n, x) ; 9,12$ recipient $S$. enteritidis $F^{-}$SH 674 (try- his- str-s $\left.H 1-g, m\right)$

\begin{tabular}{|c|c|c|c|c|c|c|c|c|c|c|c|c|}
\hline \multicolumn{2}{|c|}{$\begin{array}{l}\text { Selected marker } \\
\text { from }\end{array}$} & \multicolumn{2}{|c|}{$\begin{array}{c}\begin{array}{c}\text { Recombi- } \\
\text { nants }\end{array} \\
\text {. }\end{array}$} & \multirow[b]{2}{*}{ O serotype } & \multicolumn{8}{|c|}{ Markers tested (in their proposed map order) } \\
\hline $\begin{array}{c}H f r \\
\text { donor }\end{array}$ & $\begin{array}{c}F \text {-reci- } \\
\text { pient }\end{array}$ & no. & $\%$ & & try & H1 & his & $0-4 / 9$ & $O-5$ & aro & $\mathrm{H} 2$ & $s t r$ \\
\hline his $^{+}$ & aro $^{+}$ & $\begin{array}{r}21 \\
21 \\
7 \\
49\end{array}$ & $\begin{array}{l}43 \\
43 \\
14\end{array}$ & $\begin{array}{l}9,12 \\
4,12 \\
4,5,12\end{array}$ & $\begin{array}{l}\mathbf{R} \\
\mathbf{R} \\
\mathbf{R}\end{array}$ & $\begin{array}{l}\mathbf{R} \\
\mathbf{R} \\
\mathbf{R}\end{array}$ & $\begin{array}{l}\mathbf{D} \\
\mathbf{D} \\
\mathbf{D}\end{array}$ & $\begin{array}{l}\mathbf{R} \\
\mathbf{D} \\
\mathbf{D}\end{array}$ & $\begin{array}{l}\overline{\mathbf{R}}^{*} \\
\mathbf{D}\end{array}$ & $\begin{array}{l}\mathbf{R} \\
\mathbf{R} \\
\mathbf{R}\end{array}$ & $\begin{array}{l}\mathbf{R} \\
\mathbf{R} \\
\mathbf{R}\end{array}$ & $\begin{array}{l}\mathbf{R} \\
\mathbf{R} \\
\mathbf{R}\end{array}$ \\
\hline try $y^{+}$ & aro $^{+}$ & 10 & 100 & 9,12 & D & $\mathbf{R}$ & $\mathbf{R}$ & $\mathbf{R}$ & $\mathbf{R}$ & $\mathbf{R}$ & $\mathbf{R}$ & $\mathbf{R}$ \\
\hline
\end{tabular}

$\mathrm{R}$ represents the recipient $\left(F^{-}\right)$allele, $D$ the donor $(H f r)$ allele. $*$-indicates no reaction in anti-5 immune serum, which perhaps is not an adequate test for the presence of $0-5$ in these recombinants (see discussion, p. 63). The alleles used in selection in bold face. For abbreviations see Fig. 2.

small part of the donor chromosome. However, when the donor hist allele was selected, $57 \%$ of the recombinants had the 4-specificity of the donor instead of the 9 of the recipient. All the recombinants tested showed strong and typical O-agglutination in either anti-4 or anti-9 serum, and none had both of these specificities. Thus the partial antigens 4 and 9 behaved as if determined by alleles of one locus, which might be called $O-4 / 9$, approximately $60 \%$ linked to his. 
The specificities 4 and 5 were separated in several cases. Indeed there were more 4,12 than 4,5,12 recombinants although the donor was 4,5,12. None of the recombinants with the partial antigen 9 had 5 -specificity. If the order of the loci concerned is:- $h i s-0-4 / 9-0-5-$ such recombinants are not to be expected since the incorporation of his and $0-5$ from the donor without that of $0-4$ requires a quadruple crossover. They are, however, to be expected with $h i s^{+}$but without $0-4$ in the reversed cross, with a $9,12 \mathrm{his}^{+}$strain as donor to a $4,5,12 \mathrm{his}^{+}$str-r recipient (see below).

When the donor try ${ }^{+}$allele was selected instead of $\mathrm{his}^{-}$, all recombinants had completely recipient-like $\mathrm{O}$ antigens. They also all had the recipient his $^{-}$. Both $\mathrm{his}^{+}$and $\mathrm{try}^{+}$were simultaneously selected from the donor in the hope of obtaining the integration of the whole try-his segment in many recombinants. If $O-4 / 9$ or $O-5$

Table 2. Cross 2. 9,12 donor Salmonella enteritidis $F 59^{+}$sH 673 (try- str-s H 1-g, $m$ ); 4,5,12 recipient $S$. typhimurium $F^{-}$sL 803 (his ${ }^{-}$ath- str-r H 1-i, H 2-1,2)

Selected marker

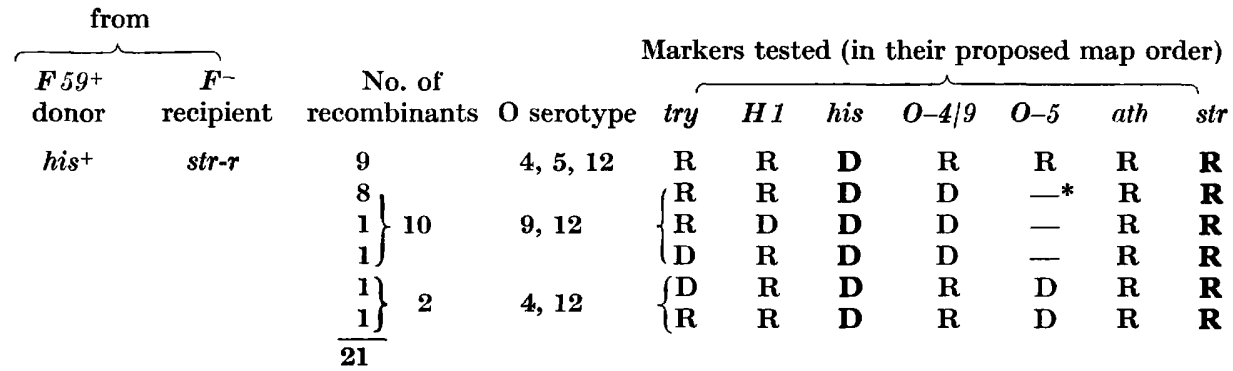

$\mathbf{R}$ represents the recipient $\left(F^{-}\right)$allele, $\mathbf{D}$ the donor $\left(F^{\prime}+\right)$ allele. *-indicates no reaction in anti-5 immune serum, which perhaps is not an adequate test for the presence of $O-5$ in these recombinants (see discussion, p. 63). The alleles used in selection are in bold face. For abbreviations see Fig. 2.

were located between try and his then all or nearly all such recombinants would be expected to have the donor $\mathbf{O}$ alleles. However, the integration of the whole segment did not occur, as indicated by the absence of the donor phase-1 flagellar antigen $b$ among the recombinants; the gene $H 1$ determining the specificity of this antigen is known to be located between his and try. The reason for this unexpected behaviour remains unknown. A high degree of chromosomal non-homology in the region might be an explanation. The $\boldsymbol{H} 1$ genes (determining the specificities $b$ for the donor, $g, m$ for the recipient) could replace each other in transduction tests.

In crosses 2 and 3 the 'reverse' cross was made, crossing a 9,12 (Salmonella enteritidis) $F^{\prime}$ donor to two $S$. typhimurium $(4,5,12)$ his- str-r $F^{-}$recipients. The results are shown in Tables 2 and 3 . The donor allele his $^{+}$was selected in both cases. Again in all recombinants either antigen 4 of the recipient or antigen 9 of the donor was fully expressed. The donor allele $O-9$ was $50 \%$ linked to his.

The partial antigens 4 and 5 were again separated, for in cross 2 of the recombinants with antigen 4 of the recipient two failed to agglutinate with anti-5 serum. These two 4,12 recombinants constitute a minority out of 17 recombinants with antigen 4 . They represent quadruple cross-overs according to the map order proposed above, which on other evidence is believed to be correct (see discussion, p. 64.) 
But according to this order a majority of the 10 recombinants with antigen 9 would have inherited the gene $\mathrm{O}-5^{+}$of the recipient. No expression of it could, however, be detected by agglutination in anti-5 factor serum. In all crosses, all recombinants were agglutinated by the anti-12 serum, as were the parent strains.

Table 3. Cross 3. 9,12 donor Salmonella enteritidis F 59+ sH 673 (tryH 1-g, m); 4,5,12 recipient S. typhimurium $F^{-}$SH 142 (his- phe- H 1-i H 2-1, 2)

Selected marker from

\begin{tabular}{|c|c|c|}
\hline $\begin{array}{l}F 59^{+} \\
\text {donor }\end{array}$ & $\underset{\text { recipient }}{F^{-}}$ & $\begin{array}{c}\text { No. of } \\
\text { recombinants }\end{array}$ \\
\hline his $^{+}$ & $t r y^{+}$ & $\left.\begin{array}{l}6 \\
6 \\
\frac{1}{13}\end{array}\right\} 7$ \\
\hline
\end{tabular}

Markers tested

(in their proposed map order)

$\mathbf{R}$ represents the recipient $\left(F^{-}\right)$allele, $\mathbf{D}$ the donor $\left(F^{\prime}\right)$ allele. *- indicates no reaction in anti-5 immune serum, which perhaps is not an adequate test for the presence of $0-5$ in these recombinants (see discussion, p. 63). The alleles used in selections are in bold face. For abbreviations see Fig. 2.

\section{DISCUSSION}

Let us first examine what is known of the chemical structure of the $\mathrm{O}$ antigens 4,(5),12 and 9,12 with which the experiments were concerned. According to recent results the repeat units of the respective lipopolysaccharides are very much alike. Figure 3 shows their proposed structure, where the only known difference is in a terminal di-deoxyhexose attached to a mannose unit (Westphal \& Lüderitz, 1960; Staub, 1964); in group B this di-deoxyhexose is abequose, i.e. 3,6-di-deoxy-Dgalactose, in group D tyvelose, i.e .3,6-di-deoxy-D-mannose. These sugars are the most important determinants of the partial antigens 4 or 9.

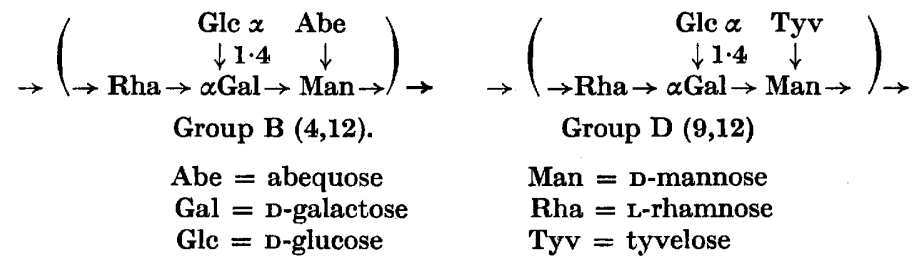

Fig. 3. The proposed structure of the $O$ repeat unit of the lipopolysaccharide of group B $(4,12)$ and group D (9,12) Salmonella strains (Staub, 1964).

The partial antigen 5, when present, is determined by an O-acetyl group on the galactose moiety (Kotelko, Staub \& Tinelli, 1961). Other aspects of the same repeat unit represent the antigen factor 12, but do not require further attention here, as the experimental data give no information about it.

In crosses between group $B(4,5,12)$ and group $D(9,12)$ bacteria, irrespective of which was the donor or recipient, the partial antigens 4 and 9 replaced each other as if determined by allelic genes.

Both the di-deoxyhexoses mainly concerned with these specificities are very uncommon, being found only in these specific antigens (and certain other $\mathbf{O}$ antigens 
of some other Gram-negative genera). Therefore it is improbable that either parent was able to synthesize both of them. In fact an enzymic conversion of a common precursor, cytidine-diphospho-glucose (synthesized by both group B and D bacteria), to cytidine-diphospho-abequose by extracts of Salmonella typhimurium (group B), or to cytidine-diphospho-tyvelose by extracts of $S$. enteritidis (group D) was recently demonstrated (Nikaido \& Jokura, 1961; Drs H. and K. Nikaido, personal communication). Thus a donor-type (in respect of $\mathbf{O}$ antigen) recombinant must have inherited from the donor parent the genes for all the enzymes leading to the synthesis of the donor-type di-deoxyhexose, and probably also a gene for a transferase needed to carry this sugar from its cytidine-diphosphate precursor compound to its place in the lipopolysaccharide. The number of different enzymes involved is not known but must be more than one; each of these enzymes must be specified by a separate structural gene. Because all recombinants had either donor-like or recipient-like antigens, i.e. 4 or 9 , all these postulated genes must be located in one cluster so as to be inherited together. This cluster, the $O-4 / 9$ locus, is situated near his, the locus for histidine biosynthesis.

In naturally occurring Salmonella strains the partial antigen 5 often appears with 4,12, but never with 9,12 (or other $O$ antigens) (Kauffmann, 1954). The corresponding gene $\mathrm{O}-5^{+}$, mutation of which leads to the loss of 5 -specificity, transforming 4,5,12 bacteria into 4, 12, is situated close to his (Iseki \& Sakai, 1952; Smith \& Stocker, 1962). This finding is corroborated by the present study, too, if it be assumed that group D Salmonella lack this gene or, less probably, have a negative allele of it. In some of the crosses reported above a majority of the 9,12 recombinants must have inherited the $O_{-5} 5^{+}$gene of the $4,5,12$ parent, but no expression of it could be detected by anti-5 factor serum. However, this is not conclusive proof of the absence of acetylated galactose in these recombinants, because anti-5 serum might require for reaction a larger antigenic grouping than just the acetylated galactose. Even so, one would expect strong cross-reactions between the acetylated-galactose forms of groups $B$ and $D$, because the units on each side of the galactose are common to both groups; no such cross-reactivity was found. A more definite test would be the use as immunogens of 09 recombinants in which the presence of the gene $\mathrm{O}-\mathrm{5}^{+}$has been ascertained by genetic means, i.e. by backcrossing to a 4,12 recipient. Another possibility is that the acetyl group is transferred on to lipopolysaccharide by an enzyme whose specificity is such that only the abequosecontaining repeat unit can serve as acceptor. The absence of a variable subfactor in group D corresponding to the variable antigen 5 in group $\mathbf{B}$ makes the latter possibility more attractive. Other possibilities are not excluded, e.g. a repression of the activity of the gene $O_{-5} 5^{+}$by the (short) piece of Salmonella enteritidis genetic material incorporated in these recombinants, but are perhaps less likely. Experiments are under way to test these alternatives.

The present results indicate a linkage between $O-4 / 9$ and $h i s$ of the order of $50-60 \%$. This is a real linkage in this sort of cross and indicates quite close proximity of the loci. The crosses were made between different sero-groups (different species according to many classifications), and pertain to a chromosomal region with a high degree of known non-homology. Both these facts tend to diminish linkage; e.g. try, a proximal locus about $1 / 4$ of the map length removed from his and expected to be $50 \%$ linked to it (Hayes, 1964; Smith \& Stocker, 1962) shows 
only $3 \%$ linkage. Another factor tending to diminish linkage between the $O$ loci and his in these crosses is the fact that the $O$ loci are probably further from the 'point of origin' of the donors than the selected locus his. $O-5$ shows even less linkage to his. The extent of this linkage cannot, however, be accurately estimated because it is not possible to test for the presence of $\mathrm{O}_{-5} 5^{+}$in all recombinant classes. In cross 1 this linkage is $14 \%$ or slightly more. Again, $O-5$ is probably further from the point of origin than both his and $0-4 / 9$ (see below).

From the data presented it is not possible to determine on which side of his the $O$ loci lie, indeed not eren whether $O-4 / 9$ and $O-5$ are on the same side or not. From other crosses, between group $\mathrm{C}$ (antigens 6, 7 and 6, 8) and group B Salmonella (Mäkelä, unpublished), it has become apparent that $0-4$, which seems allelic to $O-7$ and $0-8$ as well as to $O-9$, is between his and str and not between his and try, i.e. the order is try-H1-his-O-4/7/8/9-O-5-ath-H2-str (see Fig. 2). This is map order used in the tables above and fits all the data. It also fits the map position of $O-5$ inferred by Smith \& Stocker (1962).

It is possible that many of the rou-B mutants linked to his in Salmonella typhimurium (Subbaiah \& Stocker, 1964) have occurred with in the compound O locus now described. Evidence to this effect has been obtained from crosses of some rou-B mutants of $S$. typhimurium with group $C(6,7)$ smooth bacteria (Mäkelä, unpublished). If the correct repeat unit of the $\mathbf{O}$-specific side-chain is not formed, the result would be a rough bacterium with the core of the lipopolysaccharide only, as observed. Whether the partial antigen 12 is determined at the same locus could not yet be ascertained. Even so, this 'locus' would be a quite large region, containing information for the synthesis of perhaps all the smooth-specific sugars (those present only in the $\mathrm{O}$-specific part of the lipopolysaccharide), and for the transfer of these and other monosaccharides (or perhaps oligosaccharide units) on to the lipopolysaccharide being synthesized. The $\mathrm{O}-5^{+}$gene determining the acetylation of galactose units in the side-chain of $4,5,12$ bacteria in the present study was only $25 \%$ linked to $O-4$ in a cross where $O-5$ was distal to $O-4$. It might perhaps still be a part of the general $O$-locus if there were exceptionally much breakage of the chromosome in this cross. Other, unrelated genes present between $O-5$ and $O-4$ are not known. One ought to test for this possibility, e.g. in respect of the metG (methionine requirement) and tre (trehalose fermentation) loci reported to be very close to his (Sanderson \& Demerec, 1965; Subbaiah, 1964).

This study was supported in part by the Finnish Medical Research Council, and by grants from the Sigrid Juselius Foundation and from the International Federation of University Women; this aid is gratefully acknowledged.

\section{REFERENCES}

Beckmann, I., Lüderitz, O. \& WestPhal, O. (1964). Zur Immunchemie der somatischen Antigene von Enterobacteriaceae. IX. Serologische Typisierung von Salmonella-RAntigenen. Biochem. Z. 339, 401.

Beckmann, I., Subbaxah, T. V. \& Stocker, B. A. D. (1964). Rough mutants of Salmonella typhimurium. 2. Serological and chemical investigations. Nature, Lond. 201, 1299.

Furth, J. \& Landsteiner, K. (1929). Studies on the precipitable substances of bacilli of the Salmonella group. J. exp. Med. 49, 727. 
HAYES, W. (1964). The Genetics of Bacteria and their Viruses. Oxford: Blackwell.

IsEKI, S. \& SAKAI, T. (1952). A method of differentiation of bacterial variant which lost partial antigen. Proc. Japan Acad. 28, 450.

Kauffmand, F. (1954). Enterobacteriaceae. Copenhagen: Ejnar Munksgaard.

Kauffmann, F., Krüger, L., Lüderitz, O. \& Westphal, O. (1961). Zur Immunchemie der O-Antigene von Enterobacteriaceae. VI. Vergleich der Zuckerbausteine von Polysacchariden aus Salmonella S-und R-Formen. Zentbl. Bakt. (1. Abt. Orig.), 182, 57.

Kauffmann, F., Lüderitz, O., Stierlin, H. \& Westrihal, O. (1960). Zur Immunchemie der O-Antigene von Enterobacteriaceae. I. Analyse der Zuckerbausteine von Salmonella-O-Antigen. Zentbl. Bakt. (1. Abt. Orig.), 178, 442.

Kotelko, K., Staub, A. M. \& Tinelli, R. (1961). Étude immunochimique sur les Salmonella. VIII. Rôle des groupements $\mathrm{O}$ acetyls dans la spécificité du facteur 0:5. Ann. Inst. Pasteur, 100, 618.

LEDERBERG, J. (1950). Isolation and characterization of biochemical mutants of bacteria. Meth. med. Res. 3, 5.

Lüderitz, O., Beckmann, I. \& WestPhal, O. (1964). Zur Immunchemie der somatischen Antigene von Enterobacteriaceae. X. R-spezifische Strukturen in Salmonella-OAntigenen. Biochem. Z. 339, 416.

LüDERITZ, O., O'NeIll, G. \& Westrhal, O. (1960). Zur Immunchemie der O-Antigene von Enterobacteriaceae. V. Die Antigenfaktoren in isolierten Salmonella-O-Antigenen. Biochem. Z. 333, 136.

Mäкецӓ, P. H. (1963). Hfr males in Salmonella abony. Genetics, 48, 423.

Nikaido, H. \& Jokura, K. (1961). Isolation of cytidine diphosphate 3, 6-dideoxyhexoses from Salmonella. Biochem. biophys. Res. Commun. 6, 304.

Nikaido, H., Nikaido, K., Subbaiah, T. V. \& Stocker, B. A. D. (1964). Rough mutants of Salmonella typhimurium. 3. Enzymatic synthesis of nucleotide-sugar compounds, Nature, Lond. 201, 1301.

ØRSkov, F. \& ØrSkov, I. (1962). Behaviour of $E$. coli antigens in sexual recombination. Acta path. microbiol. scand. 55, 99.

Osborn, M. J., Rosen, S. M., Rothfield, L., Zeleznik, L. D. \& Horecker, B. L. (1964). Lipopolysaccharide of the Gram-negative cell wall. Science, 145, 783.

Robrins, P. W. \& Uchida, T. (1962). Studies on the chemical basis of the phage conversion of O-antigens in the E-group Salmonellae. Biochemistry (Chicago), 1, 323.

Sanderson, K. E. \& Demerec, M. (1965). The linkage map of Salmonella typhimurium. Genetics (in the Press).

Smith, S. M. \& Stocker, B. A. D. (1962). Colicinogeny and recombination. Br. med. Bull. 18, 46.

Staub, A. M. (1964). The role of the polysaccharide moiety in determining the specificity and immunological activity of the O-antigen complex of Salmonellae. In Bacterial Endotoxins, Ed. by M. Landy \& W. Braun. p. 38. New Brunswick, N.J.: Rutgers University Press.

Staub, A. M. \& Pon, G. (1956). Étude immunochimique sur les Salmonella. 1. Polyosides extraits de $S$. typhi, S. paratyphi B. et S. typhimurium. Ann. Inst. Pasteur, 90, 441.

Staub, A. M., Tinelli, R., Lüderitz, O. \& Westrhal, O. (1959). Étude immunochimique sur les Salmonella. V. Rôle de quelques sucres, et en particulier des 3,6-didesoxyhexoses, dans la spécificité des antigens $\mathrm{O}$ du tableau de Kauffmann-White. Ann. Inst. Pasteur, 96, 303.

Stocker, B. A. D., Zinder, N. \& Lederberg, J. (1953). Transduction of flagellar characters in Salmonella. J. gen. Microbiol. 9, 410.

Subbaiah, T. V. (1964). Ph. D. Thesis, University of London.

Subbaiah, T. V. \& Stocker, B. A. D. (1964). Rough mutants of Salmonella typhimurium. 1. Genetics. Nature, Lond. 201, 1298.

Uchida, T., Robins, P. W. \& Luria, S. E. (1963). Analysis of the serologic determinant groups of the Salmonella E-group O-antigens. Biochemistry (Chicago), 2, 663.

Westphal, O. \& Lüderitz, O. (1960). 3,6-Didesoxy-hexosen-Chemie und Biologie. Angere. Chem. 72, 881. 